bulk of the cells. The frequency of transformants in the peak fraction is four to eight times greater than the average transformation frequency of the culture. By collecting smaller fractions enrichment greater than this can be easily obtained.

The centrifugal fractionation of a competent culture in addition to yielding higher transformation frequencies provides a convenient method for investigating the metabolic properties of the potential transformants.

We thank Dr. O. Siddiqi for suggestions and criticism.

\section{R. N. SINGH}

M. P. Pitale

Molecular Biology Unit,

Tata Institute of Fundamental Research, Bombay.

' Nester, E. W., and Stocker, B. A. D., J. Bact., 86, 785 (1963).

2 Stocker, B. A. D., J. Bact, 86, 797 (1963).

"Nester, E. W., J. Bact., 87, 867 (1964).

${ }^{4}$ Anagnostopoulos, C., and Spizizen, J., J. Bact., 81, 741 (1961).

'Marmur, J., J. Mol. Biol., 3, 208 (1961).

- Kozinski, A. W., and Szybalski, W., Virology, 9, 260 (1959).

Szybalski, W., Experientia, 16, 164 (1960).

\section{Brief Consideration of the Meaning of the Lysogenic Conversion in Salmonella anatum Phage System}

THE unusual properties of the $\varepsilon$-group of Salmonella anatum phages to change the antigenic structure of the surface of their host bacterium first described by Uetake U, $^{1,2}$ are also interesting from the point of view of their biological meaning. The results given by Uetake seem to justify this approach. Uetake found that a non-lysogenic strain of Salmonella anatum $(A)$ with antigenic structure 3,10 and sensitive to the phage $\varepsilon-15$, when lysogenized by it, gives rise to a lysogenic strain $A(\varepsilon-15)$ with antigenic structure changed from 3,10 to 3,15 and sensitive to the phage $\varepsilon-34$. When this now strain (with antigenic structure 3,15 ) is lysogenized by $\varepsilon-34$, the resulting strain, containing both prophages $A(\varepsilon-15, \varepsilon-34)$, has again a new antigenic structure (3) (15) 34 . When the original strain $A$ (with antigenic structure 3,10 ) is lysogenized in special conditions by $\varepsilon-34$ only $^{2}$, no antigenic change occurs. On the basis of a very detailed analysis the authors conclude that the information for the antigenic change was brought into the cell by the infecting phage and that for the formation of the antigen 34 a mechanism for the synthesis of antigen 15 is required, so that a "genetic co-operation" between the two phages occurs.

The results of these experiments as given by Uetake are:

\begin{tabular}{|c|c|c|c|c|c|c|}
\hline & Plaque f & ormation & & & & ption \\
\hline Strain & $\begin{array}{c}\varepsilon-15 \\
\text { virulent }\end{array}$ & $\begin{array}{c}\boldsymbol{\varepsilon - 3 4} \\
\text { virulent }\end{array}$ & $\begin{array}{c}\varepsilon-15 \\
\text { virulent }\end{array}$ & $\begin{array}{c}8-34 \\
\text { virulent }\end{array}$ & $\begin{array}{c}8-15 \\
\text { virulent }\end{array}$ & $\begin{array}{c}\varepsilon-34 \\
\text { virulent }\end{array}$ \\
\hline & + & - & + & - & + & - \\
\hline $\begin{array}{l}A(\varepsilon-15) \\
A(z-34)\end{array}$ & $\bar{t}$ & \pm & $\bar{t}$ & + & 7 & + \\
\hline $8-15,-34)$ & - & - & I & - & I & $=$ \\
\hline
\end{tabular}

Without regard to the chemical basis of this pheno menon ${ }^{4}$ we find an interesting correlation; the bacteria lysogenic for $\varepsilon-15$ do not adsorb $\varepsilon-15$, the strain lysogenic for $\varepsilon-34$ does not adsorb the phage $\varepsilon-34$, and the strain lysogenic for both phages does not adsorb either of them. Thus, the changes caused by the lysogenization seem to serve as a tool depriving the bacterial host of the affinity to the phages related to the prophages present. Apparently, the phages carry information for the changes of their own receptors on the host cell. On the other hand, the $\varepsilon-34$ phage introduced "by mistake" to the strain $A$ non-lysogenic for $\varepsilon-15$ does not cause any detectable changes of the host's surface properties.

This view throws a new light on the meaning of the lysogenic conversion in this system. The logic of this phenomenon, that is the tendency to prevent superinfection by the homologous phage, may be closely related to that of lysogenic immunity. This new barrier seems to be far more efficient, because it prevents superinfection by the relatively frequent virulent mutations which overcome the cytoplasmic immunity of the lysogenic cell. A host mutation, on the other hand, would have to be a virulent one to infect this lysogenic cell, a double mutant, which is unlikely to occur.

In view of this, it may be unnecessary to differentiate between strictly viral genes and those responsible for lysogenic conversion. The problem of the origin of the latter-so often discussed (see, for example, ref. 1, p. 504; and ref. 3, p. 209)-could merge with that of the phylogenetic origin of the phage itself. The existence of lysogenic conversion would seem to support the idea of Campbell ${ }^{5}$ that phage genes advantageous to the host would be preferred and selected during evolution because they compensate for the handicap the phage imposes on the host and thus enable the host bacteria-and therefore its phage-to survive.

Department of Microbiology,

ZDEN.KK NeUBAUER

Charles University,

Prague, Viničná 5.

${ }^{1}$ Uetake, H., and Uchida, T., Virology, 9, 495 (1959).

2 Uetake, H., and Hagiwara, S., Virology, 13, 500 (1961).

${ }^{3}$ Barksdale, L., Bact. Rev., 23, 202 (1959).

- Fuchida, T., Robbins, P. W., and Luria, S. E., Biochemistry, 2, 663 (1963).

- Campbell, A., Evolution, 15, 153 (1961).

\section{Linkage of Arginine-sensitive (ars) and Uracil-Arginine Requiring (pyrA) Loci of Salmonella typhimurium}

IsHIDSU ${ }^{1}$ has isolated a mutant (ars-1) of Salmonella typhimurium that grows normally on a minimal medium but is strongly inhibited on addition of arginine. This sensitivity to arginine can be overcome by the addition of uracil.

With the knowledge that genes controlling co-ordinated functions are often clustered together ${ }^{2}$, co-transduction experiments were performed to determine whether the ars-1 locus is closely linked to a locus for a related bio. chemical step, such as biosynthesis of arginine and (or) uracil. As can be seen in Table 1, it was found that ars-1 is closely linked to pyrA, single step mutants of which require both uracil and arginine ${ }^{3}$ (see Sanderson and Demerec $^{4}$ for linkage map of $S$. typhimurium).

The procedure for testing for joint transduction was to grow donor phage P22 on ars-1. For each transductant plate, about $2 \times 10^{9}$ phage particles were added to $0.1 \mathrm{ml}$. of an overnight culture of each of the pyrA recipients (about $2 \times 10^{9} \mathrm{cells} / \mathrm{ml}$.) and the mixture was spread on the surface of the plate containing minimal agar. After 2 days of incubation, transductant colonies formed; these represented transfer of donor pyrA + to $p y r A$ recipient cells. The next step was to determine how many of the transductants also received the ars-1 mutational site along with the pyrA+. This was scored in two different ways: (1) transductant colonies were replica plated on to plates containing minimal agar plus $100 \mu \mathrm{g}$ of arginine $/ \mathrm{ml}$. A large fraction (Table 1) of the transductant colonics

Table 1. JOINT TRANSDUCTION OF ARGININE-SENSITIVE (ars-1) AND URACILARGININE $\left(\right.$ pyr $\left.A^{+}\right)$SITES IN $S$. typhimurium

$\begin{array}{clccc}\text { Test No. } & \text { Recipient } & \begin{array}{c}\text { No. of pyr } A^{+} \\ \text {transductants }\end{array} & \begin{array}{c}\text { No. containing } \\ \text { ars-1 }\end{array} & \begin{array}{c}\text { Percentage co- } \\ \text { transduction }\end{array} \\ 1 & \text { pyrA } 47 & 53 & 31 & 58 \\ 2 & \text { pyrA127 } & 58 & 32 & 55 \\ 3 & \text { pyrA129 } & 106 & 32 & 30 \\ 4 & \text { pyrA130 } & 146 & 87 & 60 \\ 5 & \text { pyrA } 130 & 92 & 41 & 45 \\ 6 & \text { pyrA } 130 & 106 & 44 & 41 \\ 7 & \text { pyr } A 130^{*} & 121^{*} & 0^{*} & 0^{*}\end{array}$

- Control, in which wild type ars-1+ donor phage was substituted for ars-1. 